\title{
Identifying periodontitis risk factors through a retrospective analysis of 80 cases
}

\author{
Jing Guan ${ }^{1}$, Dong Zhang ${ }^{2}$, Cailing Wang ${ }^{3}$
}

\begin{abstract}
Objectives: To investigate periodontitis risk factors and to establish a reference framework for identifying factors that place individuals at greater risk for periodontitis.

Methods: Clinical data from 80 periodontitis patients admitted in the Department of Stomatology at Hebei Provincial People's Hospital and treated between March 2020 and March 2021 were retrospectively analyzed.

Results: Univariate analysis showed that lower daily brushing frequencies, decreased tooth brushing duration, decreased scaling frequency, dietary habits, smoking and drinking, genetic factors, diabetes, hypertension, and obesity were more prevalent among periodontitis patients than healthy controls. Multivariate binary logistic analysis showed that daily brushing frequency, routine scaling, smoking, drinking, heredity, diabetes, hypertension, and obesity were all risk factors for periodontitis.

Conclusions: There are many risk factors for periodontitis. Clinicians need to be aware of these factors for early detection and treatment of the disease.
\end{abstract}

KEY WORDS: Periodontitis; Risk factors; Ultrasonic scaling; Retrospective analysis.

How to cite this:

doi: https://doi.org/10.12669/pjms.38.1.5205

Guan J, Zhang D, Wang C. Identifying periodontitis risk factors through a retrospective analysis of 80 cases. Pak J Med Sci. 2022;38(1):293-296. doi: https://doi.org/10.12669/pjms.38.1.5205

This is an Open Access article distributed under the terms of the Creative Commons Attribution License (http://creativecommons.org/licenses/by/3.0), which permits unrestricted use, distribution, and reproduction in any medium, provided the original work is properly cited.

\section{INTRODUCTION}

Oral health is an essential part of overall health, as well as an important indicator for the presence of other diseases. Periodontitis is one of the most common oral diseases, with an incidence second only to gingivitis. It is a chronic infection of gingival and

\footnotetext{
1. Jing Guan M.D.

2. Dong Zhang M.D.

3. Cailing Wang M.D.

1-3: Department of Stomatology,

Hebei General Hospital; No. 348

Heping West Road, Shijiazhuang,

050051, Hebei Province, P.R. China.

Correspondences:

Jing Guan,

Department of Stomatology,

Hebei General Hospital; No. 348

Heping West Road, Shijiazhuang,

050051, Hebei Province, P.R. China

E-mail: jingguan@tom.com

* Received for Publication:

* Revision Received:

* Accepted for Publication:
}

August 13, 2021

August 19, 2021

September 12, 2021 periodontal tissue caused by bacterial plaques and biofilms. ${ }^{1}$ Periodontitis can destroy the integrity of tooth supporting tissue, resulting in inflammation, the formation of periodontal pockets, and alveolar bone resorption. This endangers tooth health, and is the primary cause of missing teeth in adults. ${ }^{2}$ In particular, individuals over 45 years of age suffer from gum atrophy. However, recent reports show that periodontitis incidence is increasing among younger individuals due to genetic, environmental, and diet-related factors. ${ }^{3}$ Studies have shown that the reduction or elimination of growth hormone secretion seriously inhibits the body's absorption of vitamin C, leading to oral and gingival malnutrition.

Periodontitis has been historically difficult to cure, being very prone to relapse. Therefore, early identification and prevention of periodontitis, as well as the complete elimination of periodontitis with the aim of preventing relapse, is important. To do this, risk factors need to be identified. Previous studies indicate that periodontitis etiology is multifactorial, including heredity, living habits, 
and eating habits. Here, we study 80 cases of periodontitis admitted and treated at our hospital retrospectively in order to identify risk factors and establish a reference poin.

\section{METHODS}

General data was obtained from 80 patients treated in the Department of Stomatology at Hebei Provincial People's Hospital between January 2020 and March 2021. Among these 80 patients, 52 were male and 28 were female. Patients ranged between 19 to 59 years of age, with the average being $39.5 \pm 8.0$ years. We also obtained data from 70 healthy controls who underwent physical examinations during the same period. This group comprised 45 males and 25 females ranging in age from 18 to 59 (average age: $37.5 \pm 7.4$ years). This study was approved by the medical ethics committee of Hebei General Hospital (Approval number: 202143, approval date: 2021 July 29).

Through consultation of the established literature, a questionnaire was compiled. Information surveyed included age, gender, body mass index, smoking and drinking, oral hygiene habits, history of tooth cleaning, diabetes, blood pressure, and medical history. Data were analyzed using SPSS (v. 22.0) software. Comparisons were evaluated using chi-squared tests.

\section{RESULTS}

Data from periodontitis patients and healthy controls were first analyzed and compared using univariate analysis. Periodontitis patients presented significantly shorter and less frequent teeth brushing sessions. Moreover, fewer periodontitis patients reported undergoing ultrasonic scaling every six months compared to the control group. Smoking and drinking was more frequent in periodontitis patients, while hereditary factors, diabetes, hypertension, and obesity were also significantly more prevalent among periodontitis patients $(\mathrm{P}<0.05$, Table-I).

Subsequent multivariate binary logistic analysis showed that brushing frequency (per day), presence of ultrasonic scaling performed every six months, smoking and drinking, hereditary factors, diabetes, hypertension, and obesity were all risk factors for periodontitis ( $P<0.05$, Table-II).

\section{DISCUSSION}

Periodontitis is a chronic infectious disease of the periodontal tissue. The occurrence and development of periodontitis is not only affected by pathogenic microorganisms, but also affected by general health, individual behaviors, and societal and inherent factors. Periodontitis is a multifactorial disease closely related to oral hygiene, hereditary factors, lifestyle, diet, diabetes, blood pressure and body weight. ${ }^{4}$ Poor personal oral hygiene will result in oral plaque accumulation and increase the pathogenicity of subgingival plaque. This, in turn, reduces host defenses, leading to periodontitis development. ${ }^{5}$ This study found significant differences in the brushing habits of periodontitis patients and healthy individuals in terms of brushing frequency per day. In addition to daily oral health maintenance through brushing, flossing and other associated practices, ultrasonic scaling (commonly known as "tooth washing") helps treat periodontitis. Here, professional medical devices remove dental calculus and subgingival plaque. As a preventive measure, individuals should undergo scaling roughly every six months. ${ }^{6}$ Proper dental care habits are paramount to maintaining periodontal tissue health and preventing disease occurrence or relapse.

Genetic factors are also risk factors for periodontitis. Agrawal AA et al. ${ }^{7}$ have found that

Table-I: Univariate analysis results of two groups of data.

\begin{tabular}{|c|c|c|c|c|c|c|c|c|c|c|c|c|c|c|c|c|}
\hline \multirow[t]{2}{*}{ Group } & \multicolumn{2}{|c|}{$\begin{array}{l}\text { Daily } \\
\text { brushing } \\
\text { frequency }\end{array}$} & \multicolumn{2}{|c|}{$\begin{array}{l}\text { Brushing } \\
\text { duration } \\
\text { (min) }\end{array}$} & \multicolumn{2}{|c|}{$\begin{array}{l}\text { Ultrasonic } \\
\text { scaling every } \\
\text { six months }\end{array}$} & \multicolumn{2}{|c|}{$\begin{array}{l}\text { Smoking and } \\
\text { drinking }\end{array}$} & \multicolumn{2}{|c|}{$\begin{array}{l}\text { Genetic } \\
\text { factors }\end{array}$} & \multicolumn{2}{|c|}{ Diabetes } & \multicolumn{2}{|c|}{$\begin{array}{l}\text { Hyperten- } \\
\text { sion }\end{array}$} & \multicolumn{2}{|c|}{ Obesity } \\
\hline & $\leq 1$ & $\geq 2$ & $\leq 1$ & $\geq 1.5$ & No & Yes & No & Yes & No & Yes & No & Yes & No & Yes & No & Yes \\
\hline Study group & 73 & 7 & 66 & 14 & 76 & 4 & 49 & 31 & 65 & 15 & 63 & 17 & 56 & 24 & 55 & 25 \\
\hline Control group & 27 & 43 & 30 & 40 & 51 & 19 & 56 & 14 & 67 & 3 & 66 & 4 & 65 & 5 & 64 & 6 \\
\hline$X^{2}$ & \multicolumn{2}{|c|}{49.395} & \multicolumn{2}{|c|}{40.259} & \multicolumn{2}{|c|}{14.1} & \multicolumn{2}{|c|}{6.25} & \multicolumn{2}{|c|}{7.397} & \multicolumn{2}{|c|}{7.484} & \multicolumn{2}{|c|}{12.507} & \multicolumn{2}{|c|}{11.711} \\
\hline $\mathrm{P}$ & \multicolumn{2}{|c|}{0.000} & \multicolumn{2}{|c|}{0.000} & \multicolumn{2}{|c|}{0.000} & \multicolumn{2}{|c|}{0.012} & \multicolumn{2}{|c|}{0.007} & \multicolumn{2}{|c|}{0.006} & \multicolumn{2}{|c|}{0.000} & \multicolumn{2}{|c|}{0.001} \\
\hline
\end{tabular}


Table-II: Multivariate binary logistic analysis of periodontitis patients.

\begin{tabular}{|c|c|c|c|c|c|c|c|c|}
\hline \multirow{2}{*}{ Risk factors } & \multirow{2}{*}{$B$} & \multirow{2}{*}{ S.E. } & \multirow{2}{*}{ Wald } & \multirow{2}{*}{$d f$} & \multirow{2}{*}{$P$} & \multirow{2}{*}{ OR } & \multicolumn{2}{|c|}{ OR $95 \% C I$} \\
\hline & & & & & & & Lower & Upper \\
\hline Gender & 1.321 & 0.842 & 2.465 & 1 & 0.116 & 3.748 & 0.72 & 19.505 \\
\hline Age & 0.143 & 0.085 & 2.812 & 1 & 0.094 & 1.154 & 0.976 & 1.364 \\
\hline Brushing frequency (per day) & 3.59 & 1.111 & 10.433 & 1 & 0.001 & 36.218 & 4.102 & 319.801 \\
\hline Brushing duration (min) & 0.509 & 0.623 & 0.669 & 1 & 0.413 & 1.664 & 0.491 & 5.639 \\
\hline Ultrasonic scaling performed every 6 months & 3.16 & 1.621 & 3.802 & 1 & 0.051 & 23.579 & 0.984 & 565.109 \\
\hline Smoking and drinking & -2.237 & 0.953 & 5.508 & 1 & 0.019 & 0.107 & 0.016 & 0.691 \\
\hline Genetic factors & -3.169 & 1.208 & 6.886 & 1 & 0.009 & 0.042 & 0.004 & 0.448 \\
\hline Diabetes & -4.606 & 1.314 & 12.292 & 1 & 0.000 & 0.01 & 0.001 & 0.131 \\
\hline Hypertension & -5.225 & 1.998 & 6.836 & 1 & 0.009 & 0.005 & 0 & 0.27 \\
\hline Obesity & -3.145 & 0.95 & 10.969 & 1 & 0.001 & 0.043 & 0.007 & 0.277 \\
\hline
\end{tabular}

periodontitis inflammation is largely caused by the pro-inflammatory cytokine interleukin-1 (IL1). Differences in IL-1-related gene expression can therefore cause individuals to respond differently to the same levels of plaque. As such, certain IL-1 genotypes may serve as a risk factor for severe chronic periodontitis. Further, Nibali L, et al. ${ }^{8}$ conducted a meta-analysis investigating genetic factors for periodontitis, finding that the heritability $\left(\mathrm{H}_{2}\right)$ of periodontitis was 0.38 , indicating that roughly one-third of periodontitis variants may result from genetic factors. Moreover, heritability appears to increase with disease severity. ${ }^{9}$ The results also show that genetic factors are one of the risk factors for periodontitis.

Lifestyle habits can also endanger periodontal tissue health. Kirschneck C. ${ }^{10}$ showed that nicotine exposure increased periodontal bone loss and increased tooth movement velocity in an animal model. Similarly, alcohol consumption has been linked to elevated circulating neutrophil levels, which promotes periodontitis initiation through the release of reactive oxygen species intermediates, cationic peptides, and matrix metalloproteinases (MMPs) ${ }^{11,12}$ The consumption of certain foods has also been linked to periodontitis. The study found that the prevalence of smoking and drinking in periodontitis patients was higher than in the control group. In addition, Chang $\mathrm{YC}^{13}$ noted that betel nut chewing was linked to a higher prevalence of periodontal disease. The main chemical component of the betel nut is arecoline, which inhibits cell proliferation and reduces protein synthesis. Furthermore, nicotine has a synergistic effect on arecoline-induced cytotoxicity, meaning that certain combinations of behaviors-in this case, betel nut consumption and smoking-results in elevated periodontitis risk.

Epidemiological data presents diabetes as a major risk factor for periodontitis, with diabetics at three-fold greater risk for disease development. Along these lines, the severity of hyperglycemia has also been linked to periodontitis severity. The precise mechanism underlying this relationship is not well understood, but involves immune system function, neutrophil activity, and cytokine production. ${ }^{14}$ Reciprocally, Genco RJ, et $\mathrm{al}^{15}$ reported that periodontal disease negatively affected blood glucose control and diabetes complications. Finally, diabetes is a risk factor for tooth loss, which in turn may contribute to periodontitis etiology. ${ }^{16}$ This study found that more periodontitis patients had diabetes mellitus.

Hypertension is an independent risk factors of periodontitis, with potential ramifications on cardiovascular disease (CVD) complications. Hypertension, in particular, is associated with many mechanisms such as low-grade systemic inflammation and redox imbalance that render individuals more susceptible to periodontitis. ${ }^{17} \mathrm{In}$ hypertensiveindividuals, microcirculation changes can cause periodontal tissue ischemia, a promoting factor for periodontal diseases. ${ }^{18}$ Conversely, studies have also shown that periodontitis can lead to increased blood pressure and decrease the effectiveness of antihypertensive therapeutics. ${ }^{19}$ This study also shows that hypertension is one of the independent risk factors for periodontitis, which is consistent with the literature.

Finally, increased body mass index, waist circumference, subcutaneous fat proportion, and blood lipid levels are all associated with increased 
periodontitis risk. The mechanisms underlying this relationship may involve adipose tissuederived cytokines affecting systemic metabolism and creating low-grade systemic inflammation. ${ }^{20}$ Chaffee et al. ${ }^{21}$ conducted a systematic review on the relationship between chronic periodontitis and obesity, finding 41 of 70 investigated studies showing obesity to be associated with periodontitis. This study also found that the amount of tooth attachment loss was greater in obese patients with periodontitis. This study found that 25 people in the periodontitis group were obese, a much higher prevalence than the normal group.

\section{CONCLUSION}

The findings of this study largely concur with prior reports highlighting the diversity of risk factors for periodontitis, and can serve as a reference for clinical treatment. It must be noted that this study contains a small sample size and investigates a culturally and ethnically homogenous population. Further research is necessary in the future to better clarify the relationship between various risk factors and periodontitis in order to reduce disease incidence and improve quality of life.

\section{REFERENCES}

1. Fine DH, Patil AG, Loos BG. Classification and diagnosis of aggressive periodontitis. J Clin Periodontol. 2018;45(Suppl20):S95-S111. doi: 10.1111/jcpe.12942

2. Martin-Cabezas R, Davideau J-L, Tenenbaum H, Huck O. Clinical efficacy of probiotics as an adjunctive therapy to non-surgical periodontal treatment of chronic periodontitis: a systematic review and meta-analysis. J Clin Periodontol. 2016;43(6):520-530. doi: 10.1111/jcpe.12545

3. Garrido M, Cárdenas AM, Astorga J, Quinlan Francisca, Valdes Macarena, Chaparro Alejandra, et al. Elevated Systemic Inflammatory Burden and Cardiovascular Risk in Young Adults with Endodontic Apical Lesions. J Endod. 2019;45(2):111-115. doi: 10.1016/j.joen.2018.11.014

4. Bouchard P, Carra MC, Boillot A, Mora F, Rangé H. Risk factors in periodontology: A conceptual framework. J Clin Periodontol. 2017;44(2):125-131. doi: 10.1111/jcpe.12650

5. Lertpimonchai A, Rattanasiri S, Arj-Ong Vallibhakara S, Attia J, Thakkinstian A. The association between oral hygiene and periodontitis: A systematic review and metaanalysis. Int Dent J. 2017;67(6):332-343. doi: 10.1111/ idj.12317

6. Garanayak N, Das M, Patra RC, Biswal S, Panda SK. Effect of age on dental plaque deposition and its control by ultrasonic scaling, dental hygiene chew, and chlorhexidine $(0.2 \% \mathrm{w} / \mathrm{v})$ in dogs. Vet World. 2019;12(11):1872-1876. doi: 10.14202/ vetworld.2019.1872-1876

7. Agrawal AA, Kapley A, Yeltiwar RK, Purohit HJ. Assessment of Single Nucleotide Polymorphism at IL-1A+4845 and IL-1B+3954 as Genetic Susceptibility Test for Chronic Periodontitis in Maharashtrian Ethnicity. J Periodontol. 2006;77(9):1515-1521. doi: 10.1902/jop.2006.050427
8. Nibali L, Bayliss-Chapman J, Almofareh SA, Zhou Y, Divaris K, Vieira AR. What Is the Heritability of Periodontitis? A Systematic Review. J Dent Res. 2019;98(6):632-641. doi: $10.1177 / 0022034519842510$

9. Wang C-WJ, McCauley LK. Osteoporosis and Periodontitis. Curr Osteoporos Rep. 2016;14(6):284-291. doi: 10.1007/ s11914-016-0330-3

10. Kirschneck C, Maurer M, Wolf M, Reicheneder C, Proff P. Regular nicotine intake increased tooth movement velocity, osteoclastogenesis and orthodontically induced dental root resorptions in a rat model. Int J Oral Sci. 2017;9(3):174-184. doi: 10.1038/ijos.2017.34

11. Uriarte SM, Edmisson JS, Jimenez-Flores E. Human neutrophils and oral microbiota: A constant tug-of-war between a harmonious and a discordant coexistence. Immunol Rev. 2016;273(1):282-298. doi: 10.1111/imr.12451

12. Li M, He Y, Zhou Z, Ramirez Teresa, Gao Yueqiu, Gao Yanhang, et al. MicroRNA-223 ameliorates alcoholic liver injury by inhibiting the IL-6-p47phox-oxidative stress pathway in neutrophils. Gut. 2017;66(4):705-715. doi: 10.1136/gutjnl-2016-311861

13. Chang YC, Lii CK, Tai KW, Chou MY. Adverse effects of arecoline and nicotine on human periodontal ligament fibroblasts in vitro. J Clin Periodontol. 2001;28(3):277-282. doi: 10.1034/j.1600-051x.2001.028003277.x

14. Preshaw PM, Alba AL, Herrera D, Jepsen S, Konstantinidis A, Makrilakis K, et al. Periodontitis and diabetes: A two-way relationship. Diabetologia. 2012;55(1):21-31. doi: 10.1007/ s00125-011-2342-y

15. Genco RJ, Borgnakke WS. Diabetes as a potential risk for periodontitis: Association studies. Periodontol. 2020;83(1):40-45. doi: $10.1111 /$ prd.12270

16. Mohsin SF, Ahmed SA, Fawwad A, Basit A. Prevalence of oral mucosal alterations in type 2 diabetes mellitus patients attending a diabetic center. Pak J Med Sci. 2014;30(4):716-719.

17. Del Pinto R, Pietropaoli D, Munoz-Aguilera E, D'Aiuto Francesco, Czesnikiewicz-Guzik Marta, Monaco Annalisa, et al. Periodontitis and Hypertension: Is the Association Causal? High Blood Press Cardiovasc Prev. 2020;27(4):281289. doi: 10.1007/s40292-020-00392-z

18. Macedo Paizan ML, Vilela-Martin JF. Is there an association between periodontitis and hypertension? Curr Cardiol Rev. 2014;10(4):355-361. doi: 10.2174/1573403x10666140416094901

19. Surma S, Romanczyk M, Witalinska-Labuzek J, Czerniuk MR, Labuzek K, Filipiak KJ. Periodontitis, Blood Pressure, and the Risk and Control of Arterial Hypertension: Epidemiological, Clinical, and Pathophysiological AspectsReview of the Literature and Clinical Trials. Curr Hypertens Rep. 2021;23(5):27. doi: 10.1007/s11906-021-01140-x

20. Arboleda S, Vargas M, Losada S, Pinto A. Review of obesity and periodontitis: An epidemiological view. Br Dent J. 2019;227(3):235-239. doi: 10.1038/s41415-019-0611-1

21. Chaffee BW, Weston SJ. Association between chronic periodontal disease and obesity: A systematic review and meta-analysis. J Periodontol. 2010;81(12):1708-1724. doi: 10.1902/jop.2010.100321

Authors' Contributions: JG: Conceived, designed the study and is responsible for integrity of the study. DZ \& CW: Collected the data and performed the analysis. JG: Was involved in the Writing of the manuscript and is responsible for integrity of the study. JG: Edited the manuscript. All authors have read and approved the final manuscript. 